\title{
Cause Analysis of Crack Formation in HRB400 Screw-Thread Steel
}

\author{
Pengbiao Wang1, Qichun Peng1, Sanxiang Lei' ${ }^{1}$, Youhua Wang² \\ ${ }^{1}$ Key Laboratory for Ferrous Metallurgy and Resources Utilization of Ministry of Education, \\ Wuhan University of Science and Technology, Wuhan, China \\ ${ }^{2}$ Yang Chunxin Iron and Steel Co. Ltd., Guangdong, China \\ Email: wangpengbiao@outlook.com
}

Received 3 March 2016; accepted 16 April 2016; published 19 April 2016

Copyright (C) 2016 by authors and Scientific Research Publishing Inc.

This work is licensed under the Creative Commons Attribution International License (CC BY). http://creativecommons.org/licenses/by/4.0/

c) (i) Open Access

\begin{abstract}
The analysis of the crack on the HRB400 screw-thread steel surface has been carried out by means of metallographic microscope, scanning electron microscope and EDAX. It is shown that the type of inclusions in the crack steel samples is mainly class $B$ oxide, $C$ silicate, and the inclusion size of the majority below $10 \mu \mathrm{m}$, and a small number of large inclusions are observed. The content of oxygen in the steel is high, and the carbon segregation is the main reason of the crack formation of HRB400 screw-thread steel. The measures to improve the crack formation of HRB400 screwthread steel are put forward, which provides a powerful basis for the practical production.
\end{abstract}

\section{Keywords}

HRB400 Screw-Thread Steel, Crack, Inclusion, Cause Analysis

\section{Introduction}

In the moment China HRB335II grade steel has been eliminated, HRB400III grade steel is being widely used [1]. HRB400III grade steel has many advantages such as high strength, moderate elongation and good weldability, it can enhance the structure and earthquake resistance [2]. Substituting HRB335II grade steel in the project can save $10 \%$ to $15 \%$ of the steel, and save $5 \%$ funds [3]. The steel quality is directly related to the development of national economic construction and the safety of people's life and property, so controlling the quality of rebar is particularly important. Except requirements for its chemical composition and mechanical properties, there are also strict requirements for its surface quality [4]. Crack, scarring and folding defects can't be allowed. A steel factory which produces HRB400III grade steel recently has some crack problems, and we sampled and analyzed to discover how crack formed and proposed measures to reduce or eliminate the formation of cracks. 


\section{Experimental}

\subsection{Test Material}

The sample is taken from a steel factory which produces HRB400III grade steel of diameter $20 \mathrm{~mm}, 25 \mathrm{~mm}$ and $32 \mathrm{~mm}$. The main chemical composition shows in Table 1. The steel used in the production process is: 120 tons smelting-refining-Ladle furnace-Continuous Casting-rolling. Its production of steel chemical composition requirements are as follows in Table 2.

\subsection{Test Method}

For each model of HRB400 rebar steel production appears cold bending fracture, we sampled a number of steel. These diameters are $20 \mathrm{~mm}, 25 \mathrm{~mm}$ and $32 \mathrm{~mm}$. Then the sample was processed into a $15 \mathrm{~mm} \times 15 \mathrm{~mm} \times 10$ $\mathrm{mm}$ in size. After coarse grinding, fine grinding, polishing, we used an optical microscope at 100 times the field to observe inclusion in steel and record its size. Finally we used electron microscopy (JSM-6480LV) and energy spectrum (EDAX) to analyze its compositions.

\section{Test Results and Analysis}

\subsection{Sample Microstructure}

In the national standard GB/T 13299-1991 [5], GB/T 6394-2002 under test, at 100×, 3\% alcoholic nitric acid corrosion test conditions, samples which take from crack were analyzed and compared with the qualified sample [6] The results are shown in Figure 1. Figure 1 shows the microstructure of no significant difference between the two samples (Sample microstructure are ferrite and pearlite [7], the grain size of 7.5 to 7, more coarse). Figure 1 (b) edge cracks appeared in a treaty of $0.42 \mathrm{~mm}$, nearby crack no decarbonization, large grains are found.

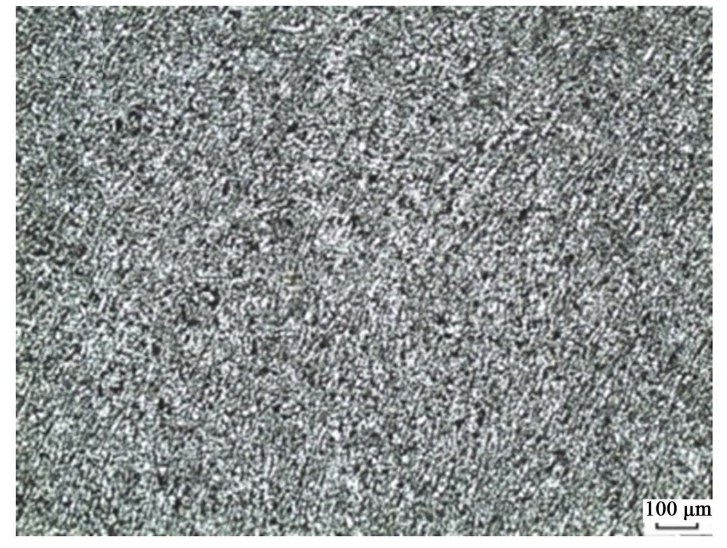

(a)

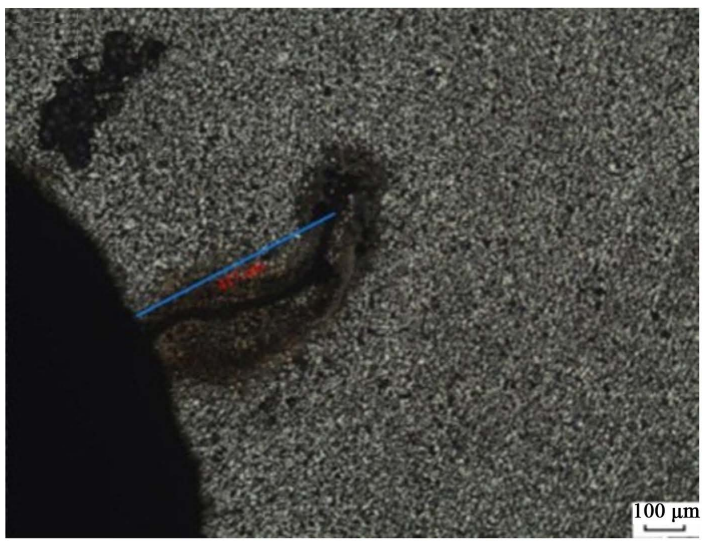

(b)

Figure 1. Comparison of microstructure of samples. (a) Normal specimen; (b) Specimen microstructure.

Table 1. Chemical composition of HRB 400 rebar (mass fraction)\%.

\begin{tabular}{ccccrr}
\hline $\mathrm{C}$ & $\mathrm{Si}$ & $\mathrm{Mn}$ & $\mathrm{S}$ & $\mathrm{P}$ & \\
\hline $0.20-0.24$ & $0.31-0.44$ & $1.08-1.21$ & $\leq 0.045$ & $\leq 0.045$ & $0.027-0.039$ \\
\hline
\end{tabular}

Table 2. HRB400 steel standard (add vanadium nitrogen alloy and micro nitrogen alloy).

\begin{tabular}{cccccccc}
\hline Specification & Composition & $\mathrm{C} \%$ & $\mathrm{Si} \%$ & $\mathrm{Mn} \%$ & $\mathrm{P} \%, \mathrm{~S} \%$ & $\mathrm{Ceq} \%$ \\
\hline $12-32$ & $\mathrm{~GB}$ & $\leq 0.25$ & $\leq 0.80$ & $\leq 1.60$ & $\leq 0.045$ & $\leq 0.12$ & 0.53 \\
$12-25$ & Content & $0.19-0.25$ & $0.25-0.45$ & $1.05-1.30$ & $\leq 0.045$ & $0.028-0.035$ \\
$28-32$ & Content & $0.19-0.25$ & $0.25-0.45$ & $1.1-1.30$ & $\leq 0.045$ & $0.035-0.042$ & $0.38-0.53$ \\
\hline
\end{tabular}


We can see that there are many pearlites and carbon segregation at the edge portion. While ambient temperature changes, it is easy to form pearlite and granular bainite-based organization at the edges, which makes the steel edges of the plastic poor and easy to form cracks [8].

\subsection{Analysis Inclusion Type}

HRB400 rebar inside of nonmetallic inclusions and surface defects within the material composition of EDS, as we can be seen from the inclusion morphology and energy spectrum (Figure 2), surface defects within the material mainly composed of iron oxides, inclusion size substantially $50 \mu \mathrm{m}$ or less, mainly due to the location of the defect in the late steel thermal processing is formed by oxidation; large pieces of steel rebar inside the elongated inclusions mainly $\mathrm{MnO}-\mathrm{SiO}_{2}$ inclusions, inclusion size $10 \mu \mathrm{m}$ or less in most and the number is small [9], major constructed of steel inclusions of oxides, sulfides, and various types of oxide complex deoxidation products oxides(e.g. manganate silicate). Among them, the inclusion of magnesium, aluminum content is high, magnesium come from the refractory material (magnesia based castable), which is caused by the erosion of the tundish [10].

As it can be seen from the spectrum detection, HRB400 rebar mainly oxide inclusions, refractory aluminous, silicate and manganese salts inclusions. Steel metallographic analysis specimens rating nonmetallic inclusions, as shown in Figure 3, inclusions rating of D3, DS2.5, B1.5, C2.

\subsection{The Type of Micro Inclusions Crack Analysis}

In order to determine the cause of HRB400 rebar crack formation, using microscope and energy spectrometer, respectively diameter of $20 \mathrm{~mm}, 25 \mathrm{~mm}, 32 \mathrm{~mm}$ HRB400 steel inclusion crack sample type are carried out test
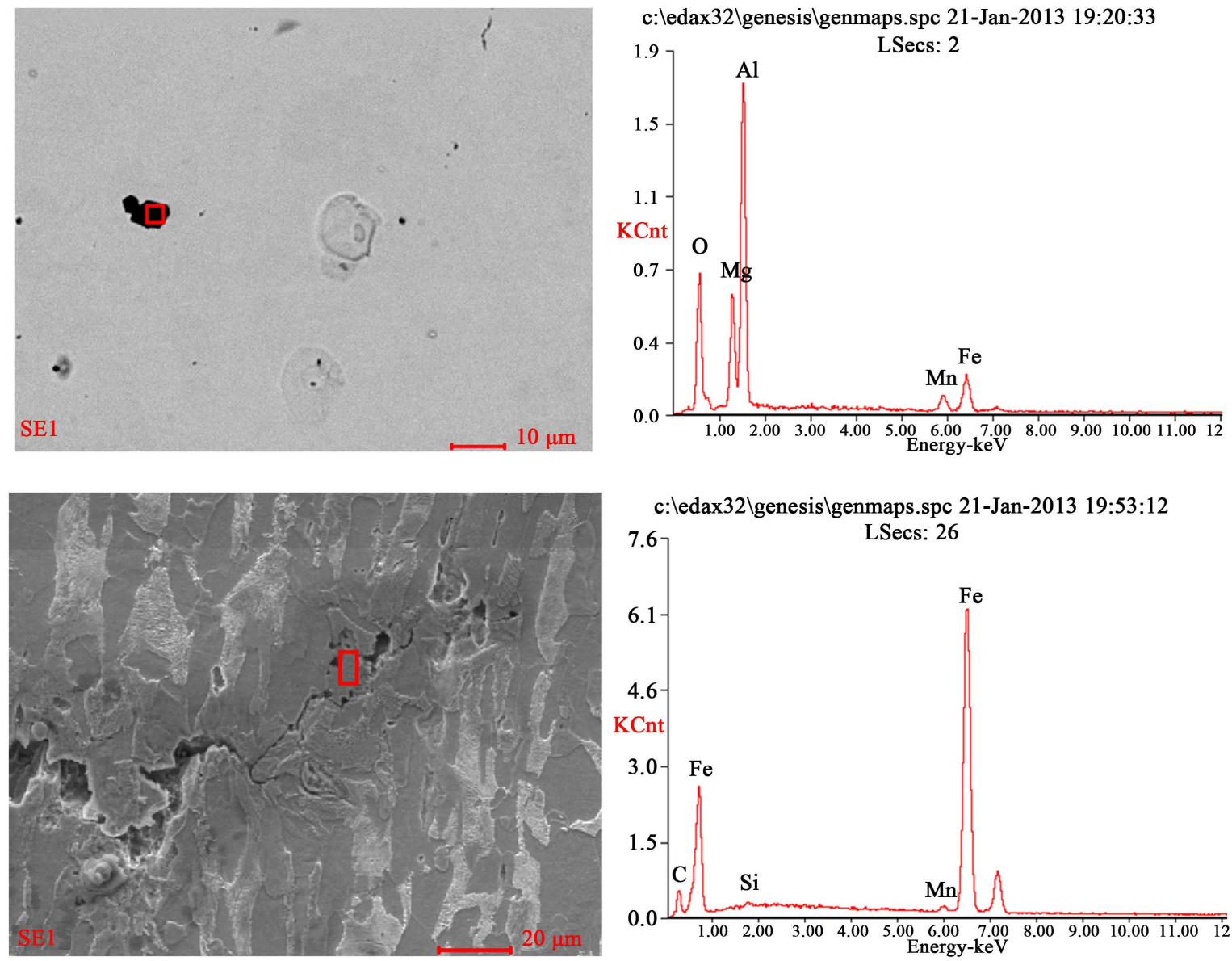

Figure 2. Morphological and energy spectrum images of inclusions. 
analysis, inclusion morphology and energy spectrum in Figures 4-6.

As can be seen from Figure 4, inclusions of the diameter of $20 \mathrm{~mm}$ HRB400 rebar cracks are the main types of $\mathrm{B}$ oxide and $\mathrm{C}$ silicate inclusions, most size below $10 \mu \mathrm{m}$.

As can be seen from Figure 5, inclusions of the diameter of $25 \mathrm{~mm}$ HRB400 rebar cracks are the main type class $\mathrm{C}$ silicates, carbon segregation crack at the serious, solid solution strengthening effect is relatively large, so that the steel plasticity and toughness decreased, resulting rebar bending flaws appear.

As can be seen from Figure 6, inclusions of the diameter of $32 \mathrm{~mm}$ HRB400 rebar cracks are the main types of $\mathrm{B}$ oxide and $\mathrm{C}$ silicate, the oxygen content is high at the crack of.
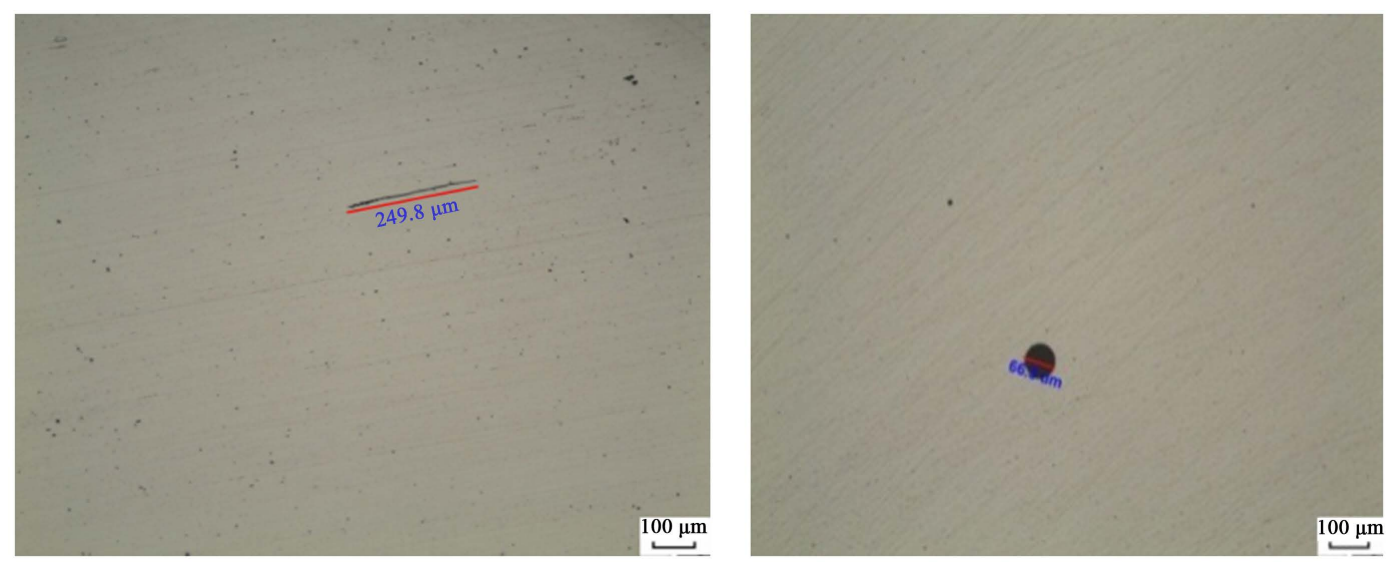

Figure 3. Inclusion grades.
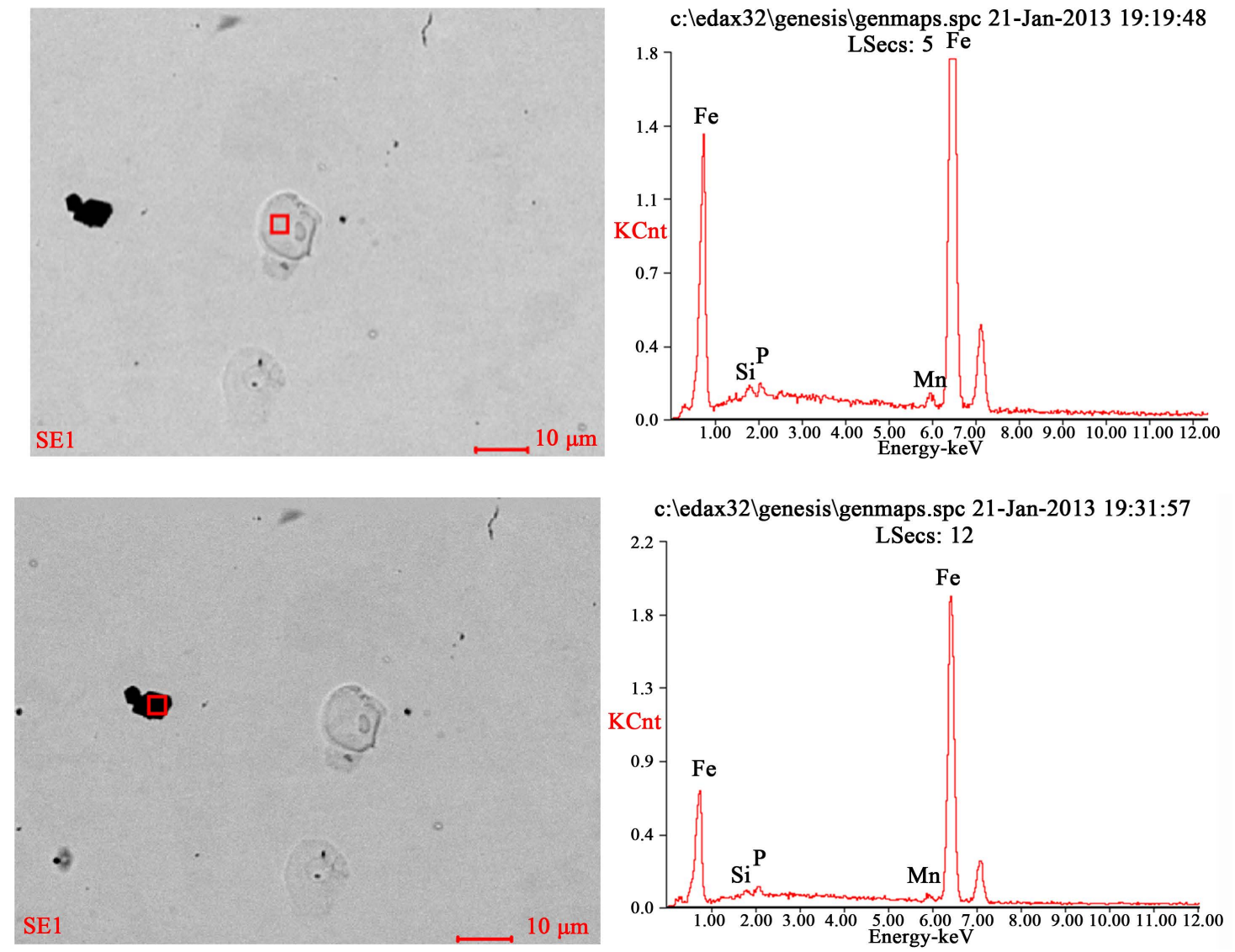

Figure 4. Inclusion morphology and energy spectrum images of samples at $20 \mathrm{~mm}$ diameter. 


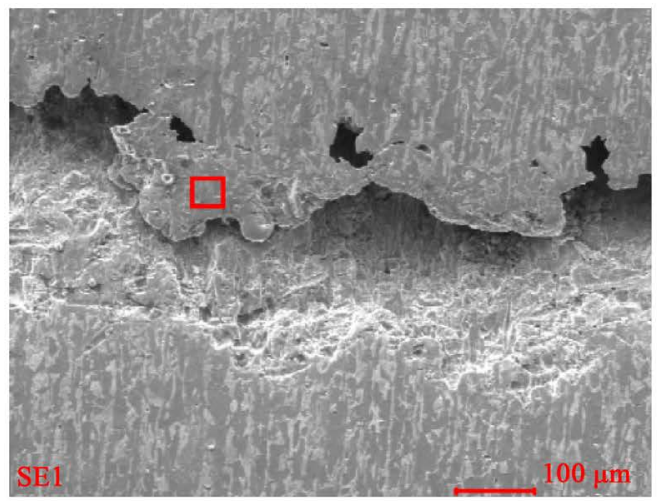

c: \edax32\genesis \genmaps.spc 21-Jan-2013 19:54:19
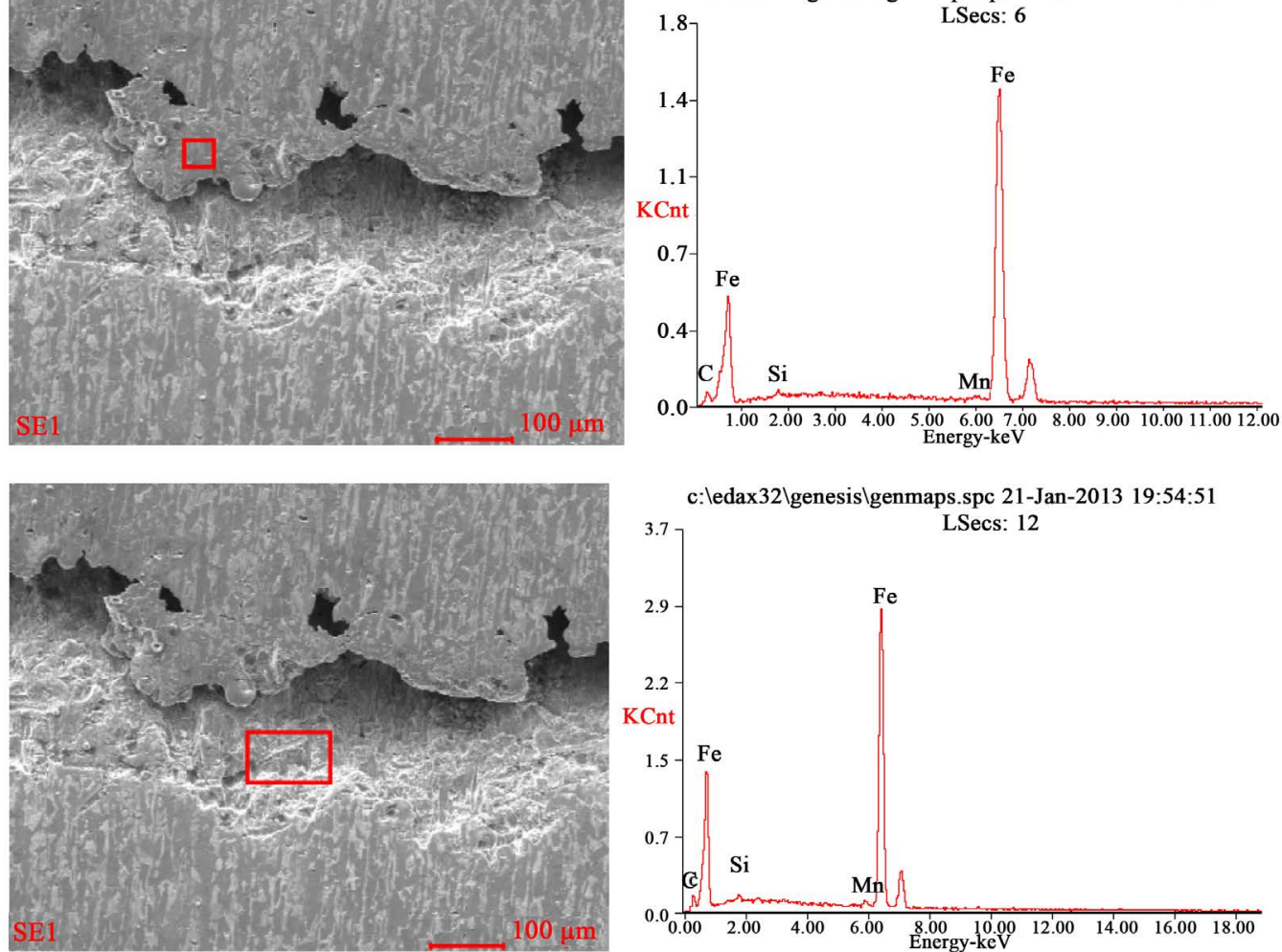

c:ledax32 \genesis\genmaps.spc 21-Jan-2013 19:54:51

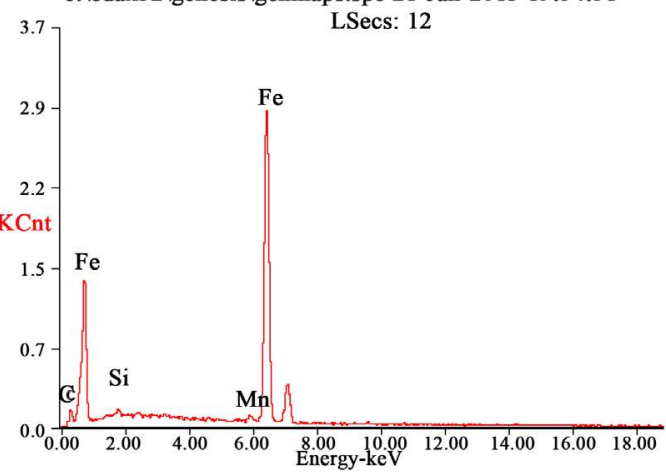

Figure 5. Inclusion morphology and energy spectrum images of samples at $25 \mathrm{~mm}$ diameter.
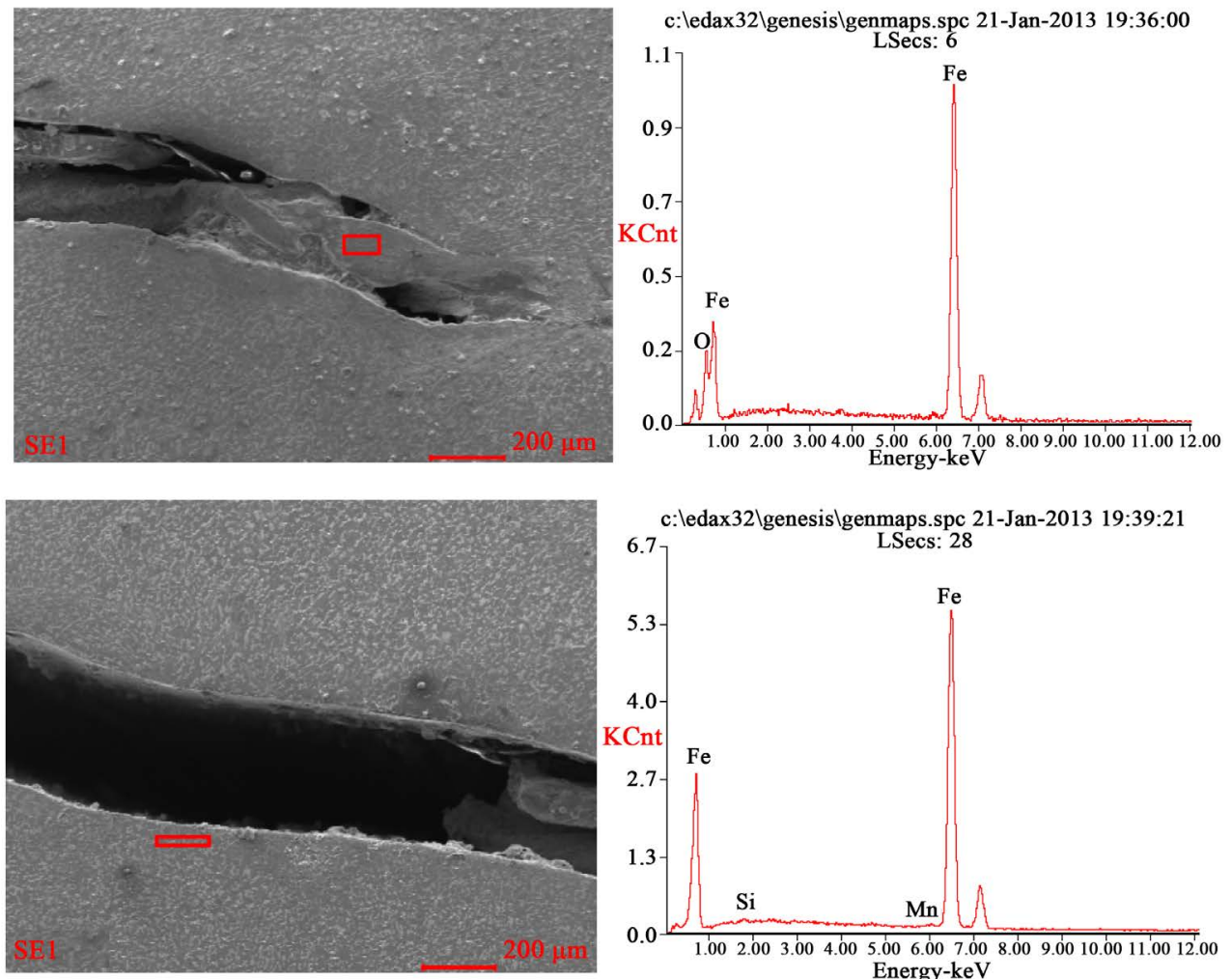

Figure 6. Inclusion morphology and energy spectrum images of samples at $32 \mathrm{~mm}$ diameter. 


\section{Conclusion and Analysis}

According to the analysis of micro-inclusions around HRB400 steel crack, we can see that the main types of inclusions in steel are Oxide (class B), Portland (class C). The reasons of the cold bending are oxygen content on the high level and carbon segregation.

In order to eliminate or reduce HRB400 rebar crack formation, the measures we take are as follows:

1) Reduction of non-metallic inclusions in steel and surface defects as possible, and improve the steel plastic. Most steel rebar surface cracks perpendicular to the surface, and the main reasons for cracking are: the bubbles under the billet skin, the exposure of the non-metallic inclusions after rolling, the casting crack, and the ripping is not clear. Thus non-metallic inclusions in steels and the surface defects have a direct relationship with the cracks formed on steel surface.

2) Control the chemical composition of the steel strictly to comply with the national standards. Si and Mn are ferrite strengthening elements. When the Mn content exceeds $1 \%$, the effect is very large; when its contents are more than $2 \%$, the effect is more significant, but it will reduce the ductility of ferrite. The content of Mn in steel is between $1.08 \%$ and $1.21 \%$, and has little effect on steel plastic.

3) Reduce the casting temperature to prevent cracks because of high superheat of liquid steel when the steel liquid of high superheat is solid. Temperature gradient is large, and the two phases are narrow, which is conducive to the development of columnar. Meanwhile, at a high temperature, the nucleation rate is low; grains grow and the limit is minor, which is not conducive to play $\mathrm{V}(\mathrm{C}, \mathrm{N})$ precipitation strengthening. It is recommended that production due to lower steel should finish rolling temperature.

4) Control of changes of ambient temperature, for example optimizing cooling rate and reducing finishing temperature, in order to prevent the formation of Widmanstatten Structure.

\section{References}

[1] Xiao, L., He, W.S. and Zhou, Y.D. (2002) Experimental Research on Electroslag Pressure Welding of HRB Grade 400 Reinoforcement. Building Construction, 24, 496.

[2] Yang, Y. (2014) Analysis on Tensile Fracture of HRB400 Rebar Welding Joint. Physics Examination and Testing, 32, 28-31.

[3] Fu, H.B., Lu, X.H. and Ma, E. (2006) Comprehensive Performance Analysis for B400 Renforced Bar. Hebei Metallurgy, No. 6, 44-47.

[4] (2007) Steel for the Reinforcement of Concrete-Part 2: Hot Rolled Ribbed Bars.

[5] Zhao, J., Chen, Y. and Chen, R. (2012) Revision Suggestion to GB/T 13299-1991 "Steel-Determination of Microstructure". Percutaneous Transluminal Coronary Angioplasty (Parta: Phystest), 48, 808-811.

[6] Gao, L.L., Yan, J.P. and Zhang, H.Z. (2009) Analysis of Unqualified Strength of 20MnSiV Hot Rolled Ribbed Bars. Physics Examination and Testing, 27, 56.

[7] Zhou, G., Zhang, J.X. and Cai, X.X. (2013) Cold Bending Fracture of HRB400 Screw Thread Steel Bar. Physics Examination and Testing, 31, 36.

[8] Mi, G.R. and Li, W.X. (1997) Reasons for Crack Formation on Ribbed Steel of 20MnSi. Journal of Baotou University of Iron and Steel Technology, 1, 42-45.

[9] Song, F.F., Yao, J.H. and Li, J.S. (2011) Research on Cleanliness and Properties of HRB400 Steel. Henan Metallurgy, 16, 8-10.

[10] Yuan, W., Lu, X.G. and Guo, S.Q. (2004) Causes of the Generation of Inclusions in 20MnSi Steel. Journal of Shanghai University, 10, 471-474. 